\title{
PATOLOGIAS ESPERMÁTICAS MAIS COMUNS EM GARANHÕES DA RAÇA PÔNEI BRASILEIRA
}

\author{
MORE COMMON SPERM PHATOLOGIES INBRAZILIAN PONY STALLIONS
}

\author{
Araújo, A.M.S. ${ }^{1}$ e Araújo, S.A.C. ${ }^{2}$
}

${ }^{1}$ Laboratório de Sanidade Animal. Centro de Ciências e Tecnologias Agropecuárias/UENF. Av. Alberto Lamego, 2000. Parque Califórnia. Campos dos Goytacazes. CEP 28015-620. Rio de Janeiro. Brasil. amanda.medvet@bol.com.br

${ }^{2}$ Laboratório de Nutrição Animal e Pastagem. Instituto de Zootecnia/UFRRJ. BR 465, km 07. Rodovia RioSão Paulo. CEP 23890-000. Rio de Janeiro. Brasil. araujosac@yahoo.com.br

\section{PalaVRas ChaVE ADICIONAIS \\ Defeito. Eqüino. Morfologia. Sêmen.}

\section{RESUMO}

Durante a domesticação, o homem transformou gradualmente os processos reprodutivos dos animais domésticos, de pastoreio livre e sistema de acasalamento estacional em intensiva produção com sistema reprodutivo abrangendo o ano inteiro. Em conseqüência, a eficiência reprodutiva dos animais domésticos declinou devido aos fatores ambientais e as demandas da produção econômica. Esses fatores podem resultar em falha reprodutiva parcial ou completa. O diagnóstico, controle e cura das desordens reprodutivas são essenciais para a indústria animal moderna. O objetivo deste trabalho foi identificar e mensurar as patologias espermáticas mais comuns dos garanhões da raça Pônei. O trabalho foi realizado em 3 propriedades particulares da cidade de Campos dos Goytacazes, Rio de Janeiro, Brasil. Foram selecionados 15 garanhões da raça Pônei Brasileiro em idade reprodutiva, já em atividade nos programas reprodutivos. Foi efetuado o esgotamento das reservas epididimárias antes do início da fase experimental. Em seguida foram coletadas amostras de sêmen, de cada garanhão a cada quinze dias, totalizando dez coletas utilizando-se vagina artificial modelo Botucatu. No laboratório de Reprodução e Melhoramento Genético Animal de Monogástricos da UENF foram realizadas as análises microscópicas para a avaliação das patologias espermáticas. A média do percentual total de defeitos encontrada nos animais deste experimento foi

Recibido: 31-10-08. Aceptado:16-12-08.

\author{
AdDitiOnAL KEYWORDS \\ Defect. Horse. Morphology. Semen.
}

$37,12 \%$ onde os defeitos maiores encontrados nos garanhões desta região foi de $28,94 \%$ e de defeitos menores $8,28 \%$. A maioria dos animais do presente experimento apresentaram um percentual médio de patologias compatível com a espécie eqüina, apresentando-se férteis, porém com percentual de patologias espermáticas acima do preconizado pelo CBRA para comercialização.

\section{SUMMARY}

During the domestication, the man turned gradually the reproductive processes of animals, from free grazing and seasonal mating system in intensive production with the reproductive system covering the entire year. Consequently, the reproductive efficiency of domestic animals declined due to environmental factors and the demands of economic production. These factors can result in partial or complete reproductive failure. The diagnosis, control and cure of reproductive disorders are essential for the modern domestic animals industry. The objective of this work was to identify and measure the most common sperm pathologies of Brazilian Pony stallions. The study was conducted in 3 private properties in the city of Campos dos Goytacazes, Rio de Janeiro, Brazil. Fifteen Brazilian Pony stallions, in reproductive age, and active in reproductive programs, were selected. The epididimary reserves were depleted before the experimental phase.

Arch. Zootec. 60 (229): 145-148. 2011. 
Semen samples of each stud were obtained every two weeks using an artificial vagina Botucatu model and totaling 10 collections. Microscopic analysis for the assessment of sperm pathologies were performed at Laboratory of Reprodução e Melhoramento Genético Animal de Monogástricos of UENF. The total number of defects found in animals of this experiment was $37.12 \%$ where, major defect reached $28.94 \%$ and minor defects $8.28 \%$. Most animals of this experiment showed an average pathology compatible with the reproduction of equine species, but sperm pathologies were above the recommended by the CBRA for marketing.

\section{INTRODUÇÃO}

Vários aspectos da endocrinologia reprodutiva são únicos aos eqüídeos. Enquanto as outras espécies animais, como bovinos, suínos e ovinos, foram altamente selecionados em função da eficiência reprodutiva, bem como de outras características produtivas, a habilidade de andar e de correr foi a única seleção pela qual os eqüídeos passaram.

Durante a domesticação, o homem transformou gradualmente os processos reprodutivos dos animais domésticos, de pastoreio livre e sistema de acasalamento estacional em intensiva produção com sistema reprodutivo abrangendo o ano inteiro. Em conseqüência, a eficiência reprodutiva dos animais domésticos declinou devido aos fatores ambientais e as demandas da produção econômica. Esses fatores podem resultar em falha reprodutiva parcial ou completa.

Bilhões de espermatozóides são produzidos a cada dia (16 milhões de espermatozóides por grama de tecido testicular por dia no garanhão). Muitas das células produzidas são defeituosas e são eliminadas através de apoptose e fagocitose pelas células de Sertoli, e outras são eliminadas no ejaculado (Heninger et al., 2004).

A espermatogênese é um longo, mas ordenado processo em que espermatozóides são produzidos nos túbulos seminíferos, e é dividida em três fases: a fase proliferativa em que a célula primária diplóide, a espermatogônia, passa por repetidas divisões mitóticas para dar origem aos espermatócitos.

No final da espermiogênese as células espermáticas já possuidoras de flagelo, porém ainda imóveis e inférteis, são liberadas para o lúmen dos túbulos seminíferos pela ação das células de Sertoli. A movimentação destas células é proporcionada pelos fluídos secretados por estas células e pelo movimento contrátil exercido pelas substâncias contidas na cápsula testicular e na camada muscular dos túbulos seminíferos (Barth e Oko, 1989).

O espermatozóide liberado pelo testículo, ao alcançar o epidídimo, ainda não possui habilidade de se movimentar, de reconhecer e fecundar o ovócito, necessitando submeter-se a transformações ao longo do epidídimo para potencializar a função de formar o zigoto (Love, 2002). O diagnóstico, controle e cura das desordens reprodutivas são essenciais para a indústria animal moderna. Este trabalho teve o objetivo de identificar e mensurar as patologias espermáticas em garanhões da raça Pônei Brasileiro para que seja estabelecido um padrão de normalidade.

\section{MATERIAISE MÉTODOS}

O trabalho foi realizado em 3 propriedades particulares da cidade de Campos dos Goytacazes, Rio de Janeiro, Brasil. Foram selecionados 15 garanhões da raça Pônei Brasileira em idade reprodutiva, já em atividade nos programas reprodutivos.

Foi efetuado o esgotamento das reservas epididimárias com uma coleta diária durante sete dias antes do início da fase experimental. Em seguida, foram coletadas amostras de sêmen, de cada garanhão $(\mathrm{n}=15)$ em intervalos de quinze dias, totalizando dez coletas. O procedimento se deu por meio de vagina artificial modelo Botucatu, onde no copo coletor já estava acoplado um 


\section{PATOLOGIAS ESPERMÁTICAS EM GARANHÕES PÔNEI BRASILEIRO}

filtro para gel. Foi utilizada égua em estro natural para auxiliar a monta na realização da coleta de sêmen.

No laboratório de Reprodução e Melhoramento Genético Animal de Monogástricos da UENF, foram realizadas as análises microscópicas para a avaliação das patologias espermáticas usando-se o método panótico rápido para observação das cabeças dos espermatozóides, onde a lâmina com o esfregaço de sêmen foi mergulhada por 10 segundos nos corantes e avaliada em microscópio imediatamente após a secagem. Para a observação da peça intermediária e cauda foi utilizado o método da câmara úmida, onde se fez a diluição em formolsalina, posteriormente o sêmen foi levado ao microscópio de contraste de fase em objetiva de imersão para análise, onde foram contadas 200 células espermáticas de cada amostra.

\section{RESULTADOSEDISCUSSÃO}

A média do percentual total de defeitos encontrada nos animais deste experimento foi $37,12 \%$ onde os defeitos maiores encontrados nos garanhões desta região foi de $28,94 \%$ e de defeitos menores $8,28 \%$. Os defeitos maiores se dividiram em: gota citoplasmática proximal $4,97 \%$, estreitamento da base da cabeça $1,89 \%$, formato piriforme da cabeça $2,53 \%$, patologias de peça intermediária $3,85 \%$, formas teratológicas $4,37 \%$, calda fortemente dobrada ou enrolada $7,23 \%$ e associação de dois ou mais defeitos $4,10 \%$. Os defeitos menores foram: gota citoplasmática distal 2,74\%, pseudogota $1,76 \%$ e calda enrolada ou dobrada 3,68\% (tabela I).

$\mathrm{Na}$ espécie eqüina, o total de defeitos entre primários e secundários, não deve ultrapassar 30\% (Colégio Brasileiro de Reprodução Animal, 1998) para o sêmen a ser comercializado. Alves et al. (2005) lendo a morfologia espermática de garanhões revelou as seguintes médias: alterações de cabeça $(8,2 \pm 2,7)$; gota citoplasmática

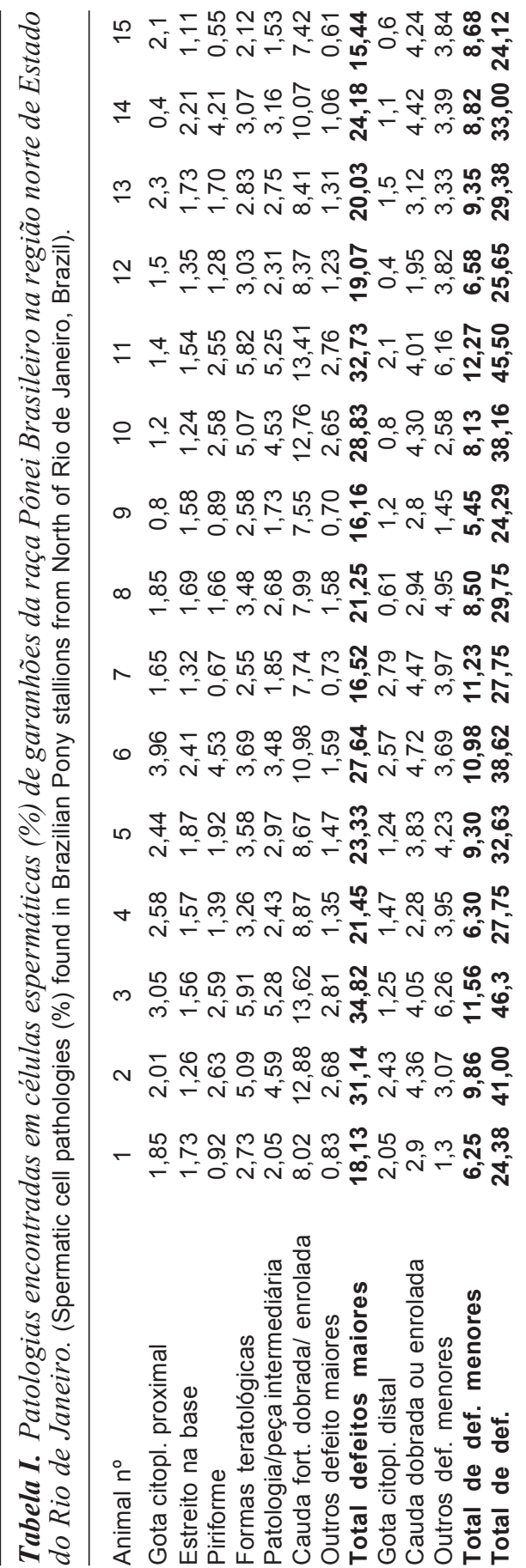

Archivos de zootecnia vol. 60, núm. 229, p. 147. 
proximal $(2,7 \pm 3,2)$; gota citoplasmática distal $(0,9 \pm 1,1)$; peça intermediária $(16,3 \pm 8,5)$; somatório das alterações da peça principal e peça terminal $(7,5 \pm 10,6)$.

Enquanto Haag (1959) verificou que melhores índices de concepção eram obtidos por garanhões que apresentavam mais de $50 \%$ de motilidade e percentuais de espermatozóides anormais inferiores a 40\%, Bielanski (1975) encontrou garanhões com altos índices de anormalidades morfológicas com excelente fertilidade. Mais tarde, Kenney et al. (1983) verificaram que a concentração espermática, a percentual de espermatozóides morfologicamente normais e a motilidade eram as características seminais que melhor explicavam a variação na taxa de prenhez obtida no fim de uma temporada de monta. Tais características serviram de base para determinar um padrão qualitativo que pudesse auxiliar na interpretação do exame de sêmen.

\section{CONCLUCÕES}

A maioria dos animais do presente experimento apresentaram uma média de pato-

\section{BIBLIOGRAFIA}

Alves, S.G., Gribeiro Filho, A.L., Snoeck, P.P.N., Chalhoub, M., Bittencourt, R.F., Portela, A.P.M., Almeida, A.K., Melo, M.I.V. e Henry, M. 2005. Efeito da solução, da fixação em formol-salina e do tempo de incubação sobre os resultados do teste hiposmótico para sêmen eqüino congelado. Ciên. An. Bras., 6: 219-225.

Barth, A.D. and Oko, R.J. 1989. Abnormal morphology of bovine spermatozoa. State University Press. Ames. lowa. 285 pp.

Bielanski, W. 1975. The evaluation of stallion semen in aspects of fertility control and its use for artificial insemination. J. Reprod. Fertil., 23 (Suppl.): 19-23.

Colégio Brasileiro de Reprodução Animal. 1998. Manual para exame andrológico e avaliação de logia compatível com a espécie eqüina, apresentando-se férteis, porém com percentual de patologias espermáticas acima do preconizado pelo CBRA para comercialização.

O elevado índice de patologias apresentado por alguns indivíduos deve-se a pouca variabilidade genética entre os indivíduos desta espécie, porque os principais reprodutores são os animais vencedores no quesito morfologia nas exposições agropecuárias, desta forma quando um garanhão é campeão torna-se muito mais valorizado economicamente, conseqüentemente a tendência natural é que ele seja mais utilizado como reprodutor. Se este for sub-fértil, seus descendentes poderão herdar suas características morfológicas, além de sua restrita capacidade reprodutiva.

\section{AGRADECIMENTOS}

Aos proprietários dos garanhões José Maurício Ferreira, Charles Jacinto e Dante Lucas por nos permitirem utilizar seus animais em nossos estudos. A Universidade Estadual do Norte Fluminense por nos proporcionar possibilidades de pesquisa.

sêmen animal. $2^{a}$ ed. Belo Horizonte. 49 pp. Haag, F.M. 1959. Evaluation of "dismount" semen in thoroughbred horse breeding. J. Amer. Vet. Med. Assoc., 1: 312-314.

Heninger, N.L., Staub, C., Blanchard, T.L., Johnson L., Varner, D.D. and Forrest, D.W. 2004. Germ cell apoptosis in the testis of normal stallions. Theriogenology, 62: 283-297.

Kenney, R.M., Hurtgen, J.P., Pierson, R. Withersponn, D. and Simons, J. 1983. Manual for clinical fertility evaluation of the stallion. Society for Theriogenology. Hastings, NE. 100 pp.

Love, C. 2002. Stallion semen evaluation and interpretation. Proceedings Society for Theriogenology. pp. 93-102. 